\title{
Penerapan Tema Simbolis pada Bentuk Rancangan Museum dan Pusat Dokumentasi Perfilman Nusantara di Surabaya
}

\author{
Siti Maria Ulfah ${ }^{1}$, Esty Poedjioetami $^{2}$, Suci Ramadhani $^{3}$ \\ 1,2,3 Jurusan Arsitektur, Fakultas Teknik Sipil dan Perencanaan, Institut Teknologi Adhi Tama Surabaya \\ Email: ${ }^{1}$ Ulfahsitimaria96@gmail.com
}

\begin{abstract}
Films in Indonesia have a long history, and are even now considered an era of national film revival, which is marked by the condition of films experiencing an ever-increasing number of production. Due to the lack of facilities available specifically for archipelago film archives in Indonesia, this background is the reason for the need to build a Museum and Archipelago Film Documentation Center located in Surabaya, where according to the Indonesian Film Agency the island of Java is the region that dominates the largest number of film viewers in Indonesia. The method used in this research is a qualitative method with descriptive research type by making observations, field studies and literature. The land chosen for the designer is located on Jalan Simpang Dukuh, Suarabaya City with an area of 0.76 hectares with a relatively flat site. The use of a symbolic theme with a representative concept was chosen so that the building being designed does not only pay attention to its function. In addition to attracting visitors with the use of symbols in the form of building design, it is hoped that it will be able to appear to show the philosophy and functions that are in it which are used as a means of education, research and entertainment just by looking at the outer appearance of a building.
\end{abstract}

Keywords: Film, Museum, Symbolic.

\begin{abstract}
Abstrak. Perfilman di Indonesia memiliki sejarah yang cukup panjang, bahkan sampai saat ini dianggap sebagai era kebangkitan perfilman nasional yang ditandai dengan kondisi perfilman yang mengalami pertumbuhan jumlah produksi yang terus meningkat. Karena minimnya fasilitas yang tersedia khusus arsip film Nusantara di Indonesia, dengan latar belakang tersebut menjadi alasan perlu dibangunnya sebuah Museum dan Pusat Dokumentasi Perfilman Nusantara yang terletak di Surabaya, dimana menurut Badan Perfilman Indonesia pulau Jawa merupakan wilayah yang mendominasi jumlah penonton film terbanyak di Indonesia. Metode yang digunakan dalam penelitian adalah metode kualitatif dengan jenis penelitian deskriptif dengan melakukan observasi, studi lapangan dan literatur. Penggunaan tema simbolis dengan konsep representatif dipilih agar bangunan yang didesain tidak hanya memperhatikan fungsinya. Selain untuk menarik pengunjung dengan penggunaan simbolieme pada bentuk desain bangunan diharapkan mampu tampil menunjukkan filosofi dan fungsi yang ada didalamnya yang tidak lain digunakan sebagai sarana edukasi, penelitian maupun hiburan hanya dengan melihat tampilan luar dari suatu bangunan.
\end{abstract}

Kata Kunci: Film, Museum, Simbolis.

\section{Pendahuluan}

Perfilman di Indonesia memiliki sejarah yang cukup panjang, bahkan sampai saat ini dianggap sebagai era kebangkitan perfilman nasional yang ditandai dengan kondisi perfilman yang mengalami pertumbuhan jumlah produksi yang terus meningkat. Berdasarkan badan Perfilman Indonesia wilayah yang merupakan penonton film terbanyak di dominasi oleh pulau jawa, di Jawa Timur salah satunya. Setelah menggali dari beberapa sumber informasi arsip film pertama di Asia Tenggara dan satu-satunya di Indonesia terletak di Gedung Pusat Perfilman H. Usmar Ismail, Kota Jakarta. Hal tersebut yang melatar belakangi pemilihan Kota Surabaya dalam merancang Museum dan Pusat Dokumentasi Perfilman Nusantara dengan menerapkan tema simbolis dengan pendekatan konsep representatif yang diharapkan mampu memberikan ciri khas bangunan Museum dan Pusat Dokumentasi Perfilman khususnya pada perfilman nusantara.

Adapun permasalahan khusus yang muncul pada proses perancangan yaitu bangaimana mewujudkan bentuk bangunan simbolis pada wujud sebuah Museum dan Pusat Dokumentasi Perfilman Nusantara di Surabaya. Dengan penerapan konsep desain bentuk yang representatif terhadap Museum 
dan Pusat Dokumentasi Perfilman diharapkan dapat menampilkan karakteristik khas dari bangunan dengan paduan bentuk dari beberapa obyek yang masih berkesinambungan dalam proses pembuatan sebuah film sehingga mempermudah pengunjung dalam memahami fungsi maupun aktivitas yang ada dalam bangunan. Oleh karena itu penulisan hasil penelitian ini bertujuan untuk mendeskripsikan transformaasi dan hasil desain secara konseptual pada Perencanaan dan Perancangan Museum dan Pusat Dokumentasi Perfilman Nusantara di Jalan Simpang Dukuh, Kota Surabaya.

\section{Tinjauan Pustaka}

Triwulan Chandra (2017) berpendapat bahwa Simbolis tidak hanya sekedar pada bentuk, tetapi mencakup tiga aspek pembentuk arsitektur yaitu form (bentuk) - meaning (makna) - function (fungsi). Simbolisme tidak dihasilkan dari sebuah kebetulan atau muncul begitu saja tanpa memiliki makna simbolisme dalam arsitektur memberikan pesan yang diutarakan dalam sebuah karya agar para pembaca dapat menemukan pertukaran makna yang terjadi pada simbol - simbol yang ada. Hal ini berkaitan dengan desain bentuk Museum dan Pusat Dokumentasi Perfilman yang menggunakan simbol dari beberapa bentuk obyek yang berkaitan dengan dunia perfilman. Selain itu pengambilan obyek juga menampilkan makna dan fungsi yang ada pada bangunan.

Menurut Denny Alamsyah Pranata Kusuma (2019), konsep representatif pada bangunan mampu memberikan pemahaman terkait fungsi dan aktivitas bangunan terhadap pengamat. Seperti halnya pada Museum dan Pusat Dokumentasi Perfilman penggunaan simbolisme yang dipilih dapat mempermudah pengamat dalam memahami aktivitas dan fungsi hanya dengan melihat tampilan saja. Dengan penggunaan konsep simbolis dengan pendekatan representatif dapat membantu menunjang penyampaian makna dan pesan yang ingin ditampilkan secara jelas.

Penggunaan simbolisme terbagi menjadi dua, yaitu : (a) Simbolisme secara langsung (penggunaan metafora secara langsung/jelas dipengaruhi oleh sifat dasar pada obyek itu sendiri, sehingga makna yang timbul dari obyek tersebut menyerupai artinya); (b) Simbolisme tidak langsung/tersamar (suatu bentuk akan memberikan suatu makna yang tersamar pada jenis bangunan tertentu yang merupakan suatu simbol yang timbul untuk memenuhi fungsi bangunan tersebut.
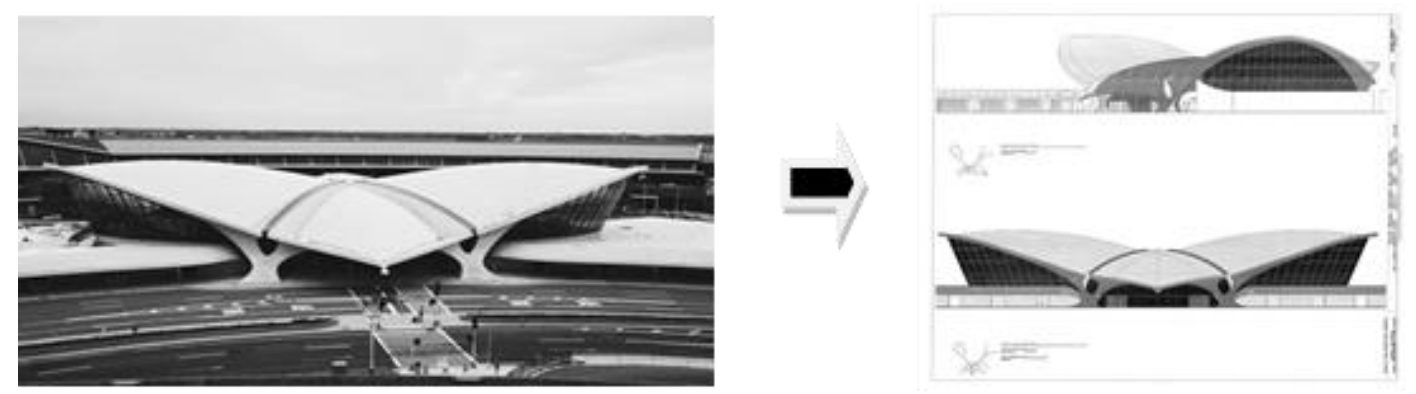

Gambar 1. Contoh simbolisme secara langsung pada "Trans World Flight Center, USA"
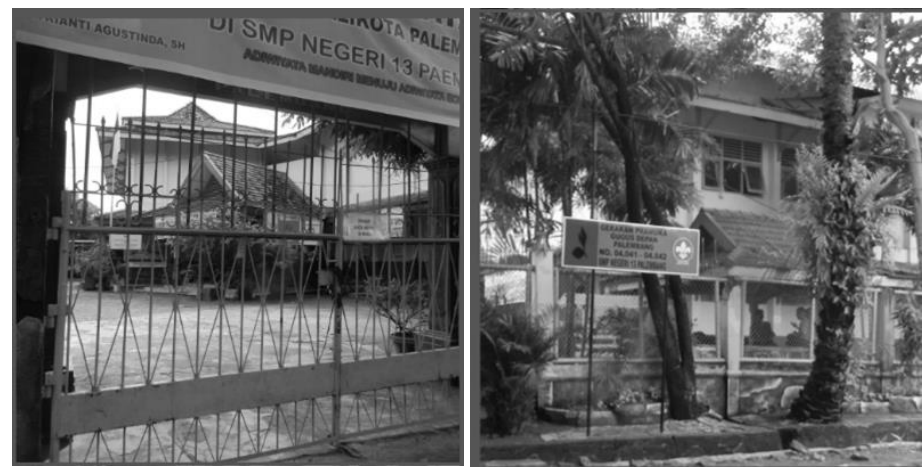

Gambar 2. Contoh simbolisme secara tidak langsung/tersamar pada "bangunan sekolah"

Pada bentuk Trans World Flight Center merupakan penerapan konsep metafora dari bentuk. Bentuk TWA didesain untuk menyimbolkan sayap burung yang tengah terbang. Hal ini di maksudkan sebagai simbol visi dri maskapai penerbangan dengan moto mereka adalah "mendapatkan Spirit penerbangan". Sedangkan pada bangunan sekolah identik dengan jendela yang berulang, dan identik 
dengan koridor yang memiliki void diruangnya. dan juga bangunan yang berbentuk seperti ini rata-rata memiliki pagar yang tinggi kesannya agar murid/siswa yang yang bersekolah tidak dapat keluar pagar saat jam pelajaran berlangsung

Metafora kombinasi merupakan proses penggabungan antara beberapa unsur yang diaplikasikan ke dalam sebuah wujud arsitektur, Muhammda Ridlo Ashari (2012). Perwujudan bentuk Museum dan Pusat Dokumentasi Perfiman Nusantara menggabungkan 3 unsur pada bentuk bangunan yaitu dari: roll film, klise film dan layar screen. Di mana ketiga unsur tersebut berkaitan dengan proses pembuatan film. Dan untuk vocal point digunakan bentuk lensa kamera yang terletak pada kolam air yang berada didepan bangunan.

(Definisi menurut ICOM = International Council of Museum / Organisasi Permuseuman Internasional dibawah Unesco). Museum merupakan suatu badan yang mempunyai tugas dan kegiatan untuk memamerkan dan menerbitkan hasil-hasil penelitian dan pengetahuan tentang benda-benda yang penting bagi Kebudayaan dan llmu Pengetahuan. Persyaratan museum menurut Pedoman Pendirian Museum (1999/2000), terdapat beberapa persyaratan yang harus diperhatikan dalam perencanaan suatu museum, antara lain: (a) Lokasi Museum : Lokasi yang strategis, Lokasi harus sehat. (b) Persyaratan Bangunan, Bangunan dikelompokkan dan dipisahkan sesuai: Fungsi dan aktivitas, Ketenangan dan keramaian, Keamanan. (c) Persyaratan Ruang, Pencahayaan dan Penghawaan, Untuk museum dengan koleksi utama kelembaban yang disarankan adalah 50\% dengan suhu 210C - 260C. Intensitas cahaya yang disarankan sebesar 50 lux dengan meminimalisir radiasi ultra violet.Ergonomi dan Tata Letak, Perletakan peraga atau koleksi berdasarkan standar-standar perletakan koleksi di ruang pamer museum yang telah ditentukan. Jalur Sirkulasi di Dalam Ruang Pamer, Jalur sirkulasi di dalam ruang pamer harus dapat menyampaikan informasi, membantu pengunjung memahami koleksi yang dipamerkan.

\section{Metode}

Metode yang digunaan dalam proses rancangan adalah metode kualitatif dengan jenis penelitian deskriptif dengan melakukan kegiatan sebagai berikut: (a) observasi, data yang diperoleh dengan melakukan pengamatan secara langsung terhadap obyek yang memiliki persamaan jenis bangunan maupun tema sebagai acuan dalam rancangan, sehingga dapat diperoleh gambaran sebagai pertimbangan dalam rancangan. (b) Dokumentasi, data yang diperoleh berupa foto - foto maupun video dari obyek yang diamati yang berfungsi sebagai pembanding dari proyek yang akan dirancang. (c) Literatur, perolehan data dari literatur baik dari jurnal maupun buku yang berisi data - data tertulis sebagai pembanding. 


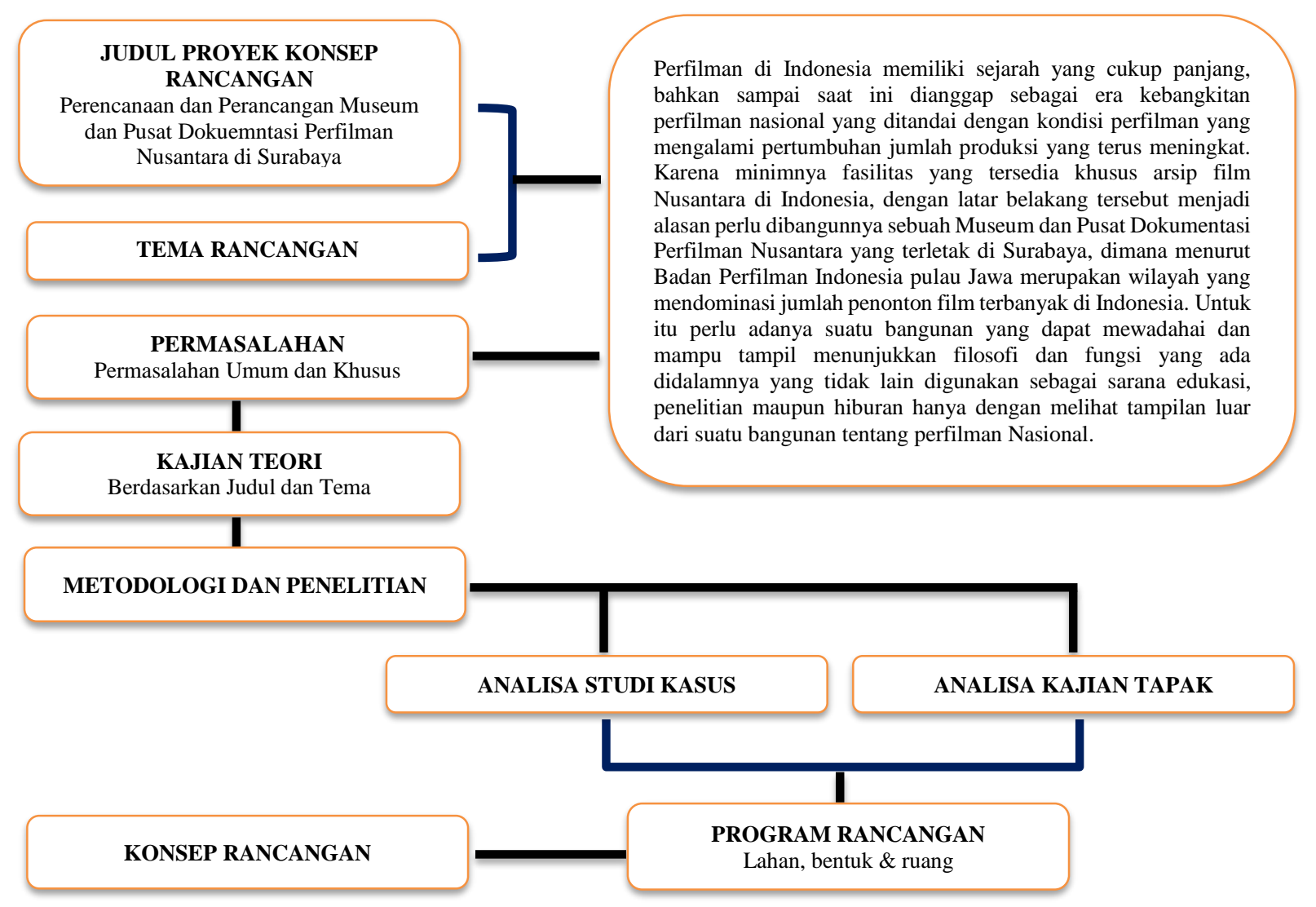

Gambar 3. Diagram Penelitian

\section{Pembahasan}

Lahan yang dipilih untuk merancang sebuah Museum dan Pusat Dokumentasi Perfilman Nusantara terletak di Jalan Simpang Dukuh, Genteng, Kecamatan Genteng, kawasan Surabaya Pusat, Kota Surabaya, Jawa Timur dengan luas lahan 0.76 Ha dengan kondisi tapak yang relatif datar. Setelah melakukan beberapa analisis terhadap lahan dapat dihasilkan kesimpulan bahwa site/lahan tersebut berpotensial untuk dibangunnya sebuah Museum dan Pusat Dokumentasi Perfilman. Karena secara kontekstual, lokasi site juga termasuk kedalam kawasan pendidikan dan komersial seperti yang tercantum pada persyaratan museum menurut Pedoman Pendirian Museum (1999/2000). Dimana area tersebut cocok untuk memperkenalkan sejarah perfilman nusantara kepada pelajar maupun masyarakat umum sebagai jejak perjalanan sejarah film yang perlu dilestarikan.

Sebelum terjadinya proses rancangan, penelitian juga melakukan kegiatan observasi dengan melakukan pengamatan secara langsung maupun melalui media website terhadap obyek yang memiliki persamaan jenis bangunan maupun tema untuk dijadikan acuan dalam proses rancangan. Hasil kegiatan observasi terhadap obyek yang dipilih adalah sebagai berikut :

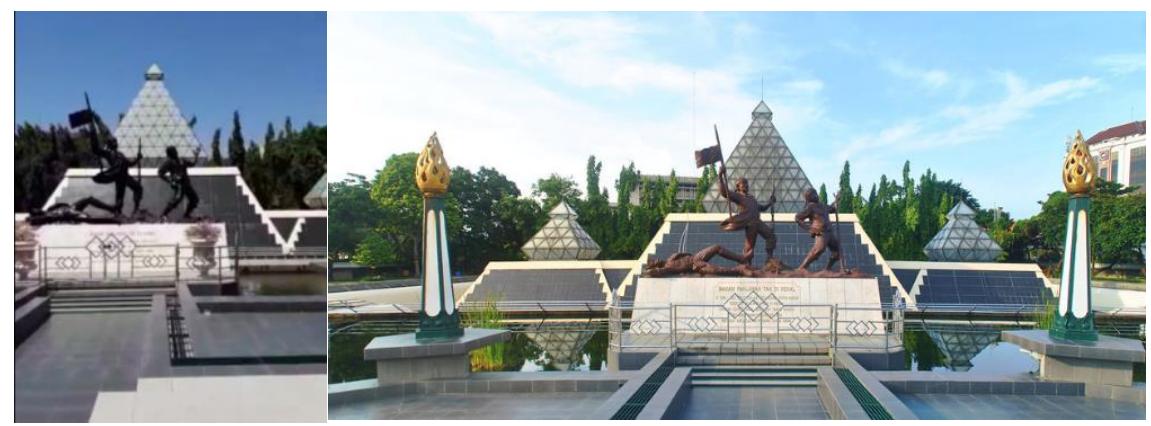

Gambar 4. Studi Kasus Museum Sepuluh November 


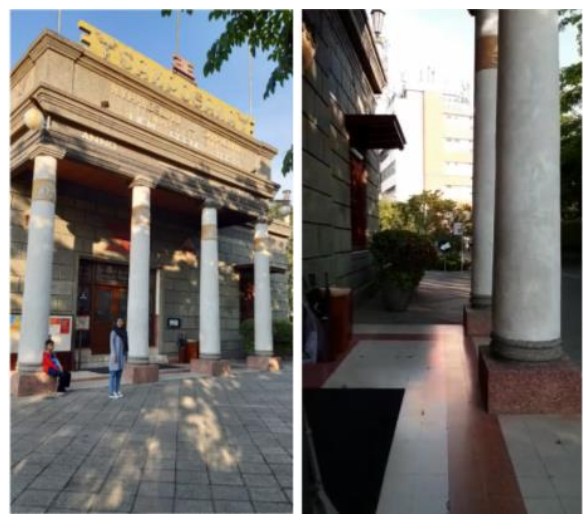

Gambar 5. Studi Kasus Museum House Of Sampoerna
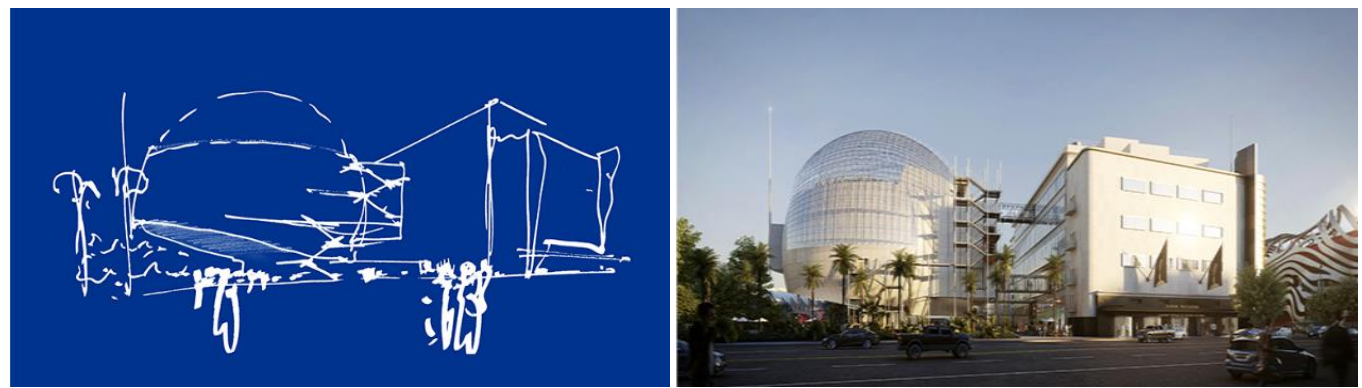

Gambar 5. Studi Kasus Academy Museum Of Motion Picture

Dari tiga studi kasus diatas yang diambil karena mempunyai persamaan dari jenis bangunan maupun tema, setelah melakukan analisis disimpulkan bahwa masing-masing obyek memiliki karekteristik yang dipengaruhi oleh fungsi dan jenis bangunan yang diaplikasikan pada tatanan bentuk, lahan maupun ruang.

Untuk tatanan lahan menggunakan konsep efektif diamana penggunaan konsep tersebut dihasilkan dengan desain yang mampu mempermudah sirkulasi dan aktivitas bagi para pengunjung maupun pengelola. Dan pada desain tatanan ruang menggunakan mikro konsep terarah dimana konsep diwujudkan dengan mengaplikasikan pembelokan dan pengelompokkan ruang agar dapat dijadikan tanda untuk mengarahkan pengunjung dari ruang ke ruang selanjutnya yang akan dituju.

Sedangkan untuk bentuk bangunan menggunakan tema simbolis dengan mikro konsep representatif metaphora kombinasi secara langsung/jelas yang menampilkan sifat dasar pada obyek itu sendiri, sehingga makna yang timbul dari objek tersebut menyerupai artinya. Penggunaan konsep tersebut bertujuan agar dapat mendesain sebuah bangunan yang mampu menampilkan karakteristik khas dari Museum dan Pusat Dokumentasi agar dapat mempermudah pengunjung dalam memahami fungsi maupun aktivitas yang ada dalam bangunan.

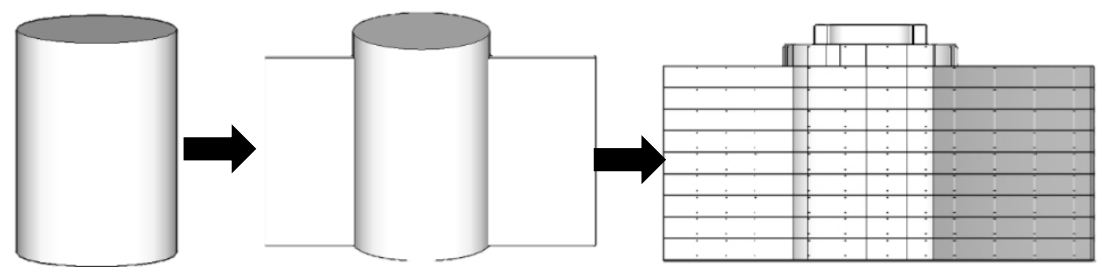

Gambar 6. Transformasi Bentuk

Berawal dari bentuk dasar yaitu tabung sebelum diolah, dimana bentuk tabung sendiri didapat dari bentuk roll film. Kemudian ditambahkan bidang di kedua sisi tabung yang dapat disebut sebagai sayap dari bangunan. Sehingga terbentuklah bangunan perpaduan bentuk tabung yang diapit 2 bidang di kedua sisinya. 


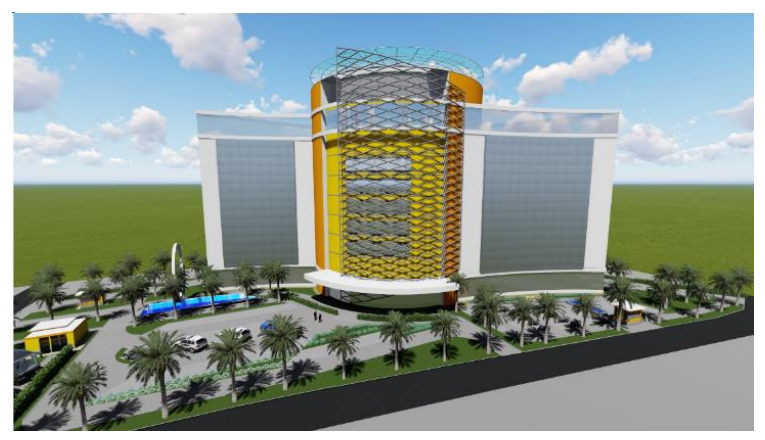

Gambar 7. Hasil rancangan bentuk bangunan

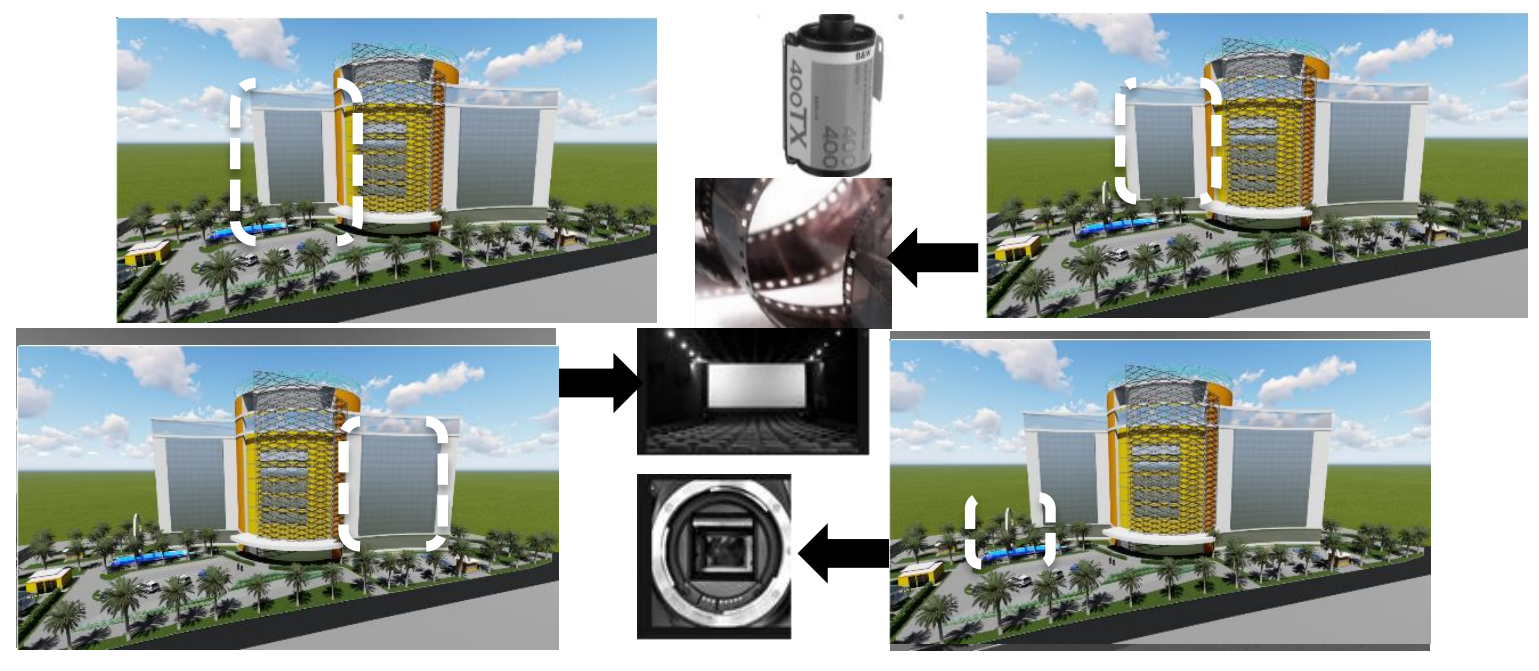

Gambar 8. Penerapan konsep terhadap bentuk

Konsep representatif metafora pada bentuk bangunan, ada dalam bentuk utama dari bangunan mengambil bentuk dari roll film seperti tabung yang dipadukan dengan warna orange sebagai finishingnya. Pada kamera analog roll film digunakan sebagai tempat penyimpanan foto dengan konsep vintage atau jadul. Alasan mengapa diambilnya bentuk dasar dari roll film ialah untuk menampilkan fungsi dari bangunan itu sendiri yang memuat berbagai foto atau video dari zaman dahulu sampai era modern sekarang. Telah kita ketahui secara umum bahwa penggunaan roll film sudah tidak digunakan lagi, melainkan sudah menggunakan peralatan yang lebih canggih.

Bentuk kerangka yang dibuat seperti melilit pada bangunan utama yang diaplikasikan sebagai space frame dan digunakan sebagai secondary skin, diartikan sebagai klise film. Jika berbicara mengenai roll film tentu tidak lepas dari klise film. Klise film merupan media yang digunakan untuk mencetak hasil foto yang ditampung pada sebuah roll film. Pengaplikasian bentuk roll film pada bangunan ditunjukkan secara secara tidak langsung/tersamar, melainkan menggunakan karakteristik dari letak klise film yang melilit pada roll film.

Kedua sayap yang menghimpit bangunan utama diambil dari bentuk screen yang digunakan untuk menayangkan atau menampilkan sebuah video, gambar atau data. Alasan mengampa ditambahkannya bentuk layar screen pada bangunan iyalah jika roll film lebih menununjukkan pada zaman dahalu maka layar screen digunakan untuk menunjukkan pada era sekarang. Layar screen biasanya digunakan pada sebuah bioskop untuk media menampilkan dan memutar sebuah film. Sama seperti halnya fungsi bangunan tersebut juga digunakan untuk menampilkan dan memutar film, karena bukan hanya untuk tempat arsip film didalamnya juga diberikan fasilitas bioskop mini yang dapat digunakan sebagi sarana hiburan bagi para pengunjung.

Sedangkan untuk bentuk lingkaran yang diletakkan pada kolam air diartikan sebagai bagian dari kamera yaitu lensa, yang digunakan untuk mengambill sebuah foto / video. Dalam proses pembuatan sebuah film dibutuhkan sebuah kamera yang digunakan untuk merekam dan menyimpan gambar dalam 
bentuk digital. Untuk itu diambillah bentuk dari bagian kamera tersebut yaitu lensa kamera. Hal ini juga diharapkan dapat menyampaikan aktivitas didalam bangunan yang terdapat fasilitas green screen dan blue screen, slow motion dan stop motion untuk membuat sebuah film untuk durasi pendek yang sangat digandrungi oleh anak muda zaman sekarang.

Dari beberapa pengertian di atas dapat disimpulkan bahwa bentuk representatif dari Museum dan Pusat Dokumentasi Perfilman Nusantara yang diambil dari bentuk gabungan antara roll film, klise film, layar screen dan lensa kamera dapat diartikan kedalam fungsi bangunan sebagai sarana dokumentasi/arsip yang menampilkan dan memutar kembali film dari zaman dulu hingga sekarang yang disertai juga dengan proses pembuatannya.

\section{Kesimpulan}

Dari pembahasan yang telah dilakukan, dapat disimpulkan penggunaan tema simbolis dengan pendekatan representatif pada rancangan museum dan pusat dokumentasi perfilman nusantara di Surabaya dapat menghasilkan tampilan bangunan yang dapat mewakili fungsi maupun aktivitas didalamnya. Dengan menggunakan bentuk gabungan antara roll film, klise film, layar screen dan lensa kamera dimana obyek-obyek tersebut berperan penting dalam proses produksi sebuah film.

\section{Referensi}

Triwulan, C. (2017). MUSEUM ALAT MUSIK NUSANTARA DI KOTA MALANG TEMA SIMBOLIS METAFORA, ITN Malang.

Azza, M. A. R. and A. Anisa (2019). "Kajian Arsitektur Simbolik Pada Bangunan Masjid." PURWARUPA Jurnal Arsit

Kusuma, D. A. P., et al. (2019). PENERAPAN KONSEP REPRESENTATIF PADA DESAIN BENTUK RUMAH SAKIT KHUSUS THT DI JOMBANG. Prosiding Seminar Teknologi Perencanaan, Perancangan, Lingkungan dan Infrastruktur.

Ashari, M. (2012). Pusat perdagangan kerajinan dan kuliner khas Sidoarjo: Tema metafora kombinasi, Universitas Islam Negeri Maulana Malik Ibrahim.

Persyaratan museum menurut Pedoman Pendirian Museum (1999/2000). 
